\title{
Effect of Wireless Sensor Networks to Increasing Causes of Numbness
}

Md Rahimullah Miah, *, A A M Shazzadur Rahman², Mohammad Abdul Hannan², Alamgir Adil Samdany4, Foujia Akhtar ${ }^{5}$, Md Sabbir Hossain ${ }^{6}$, S.A.M. Imran Hossain7, Md Shahariar Khan ${ }^{8}$, Md. Sher-E-Alam ${ }^{9}$, Jorin Tasnim Parisa $^{10}$, Mohammad Basir Uddin ${ }^{11}$, Fuad Abdullah ${ }^{12}$, Chowdhury Shadman Shahriar ${ }^{13}$, Md Mehedi Hasan ${ }^{14}$, Alexander Kiew Sayok ${ }^{15}$, Ahi Sarok ${ }^{16}$, Mohammad Belal Uddin ${ }^{17}$, Motia Begum ${ }^{18}$, Jorin Tasnim Parisa ${ }^{19}$, Md Mokbul Hossain $^{20}$, Mohammad Taimur Hossain Talukdar ${ }^{21}$, Shahriar Hussain Chowdhury ${ }^{22}$.

'Department of IT in Health, North East Medical College, Sylhet, Bangladesh and PhD Awardee from IBEC, UNIMAS (Universiti Malaysia Sarawak), Sarawak, Malaysia

${ }^{2}$ Department of Medicine, North East Medical College, Sylhet, Bangladesh

${ }^{3}$ Department of Endocrinology, North East Medical College, Sylhet, Bangladesh

${ }^{4}$ Department of Orthopedics, North East Medical College, Sylhet, Bangladesh

${ }^{5}$ Department of Economics, Moulvibazar Govt. Women's College, Moulvibazar, Bangladesh

${ }^{6}$ Department of Pathology, North East Medical College, Sylhet, Bangladesh

'Department of Oral and Maxillofacial Surgery, North East Medical College, Sylhet, Bangladesh

${ }^{8}$ Department of Paediatrics, North East Medical College, Sylhet, Bangladesh

${ }^{9}$ Department of Law, Metropolitan University, Sylhet, Bangladesh

${ }^{10}$ Govt. S.C. Girls' High Scool, Sunamganj, Bangladesh

${ }^{11}$ Department of Paediatric, North East Medical College, Sylhet, Bangladesh

${ }^{12}$ Faculty of Science, Memorial University of Newfoundland, Canada

${ }^{13}$ USMLE Student, USA and Ex-student of North East Medical College, Sylhet, Bangladesh

${ }^{14}$ Department of Law, Green University of Bangladesh, Dhaka, Bangladesh

${ }^{15}$ IBEC, Universiti Malaysia Sarawak (UNIMAS), Kota Samarahan, Sarawak, Malaysia

${ }^{16}$ Faculty of Social Science, Universiti Malaysia Sarawak, Kota Samarahan, Sarawak, Malaysia

${ }^{17 D e p a r t m e n t ~ o f ~ F o r e s t r y ~ a n d ~ E n v i r o n m e n t a l ~ S c i e n c e, ~ S h a h j a l a l ~ U n i v e r s i t y ~ o f ~ S c i e n c e ~ a n d ~ T e c h n o l o g y, ~ B a n g l a d e s h ~}$

${ }^{18}$ Lawyer, Judge's Court, Sylhet and Sunamganj, Bangladesh

${ }^{19}$ Govt. S.C. Girls' High School, Sunamgonj, Bangladesh

${ }^{20}$ Department of Pharmacology, North East Medical College, Sylhet, Bangladesh

${ }^{21}$ Associate Professor, Department of Clinical Oncology, North East Medical College, Bangladesh

${ }^{22}$ Department of Dermatology, North East Medical College, Sylhet, Bangladesh

*Corresponding author: Dr. Md. Rahimullah Miah, Head, Department of IT in Health, North East Medical College, Affiliated with Sylhet Medical University, Sylhet, Bangladesh

\section{Abstract}

Background: Numbness is a complex sensor disease in legs, feet, lower parts of the body or entire body. Yet Medical professionals are facing the insufferable supplementing causes of numbness in individual's body as a very important global health issue since the 20th century.

Objective: The study aims to evaluate the applications of the fluctuated and processed radio frequencies that effect limbs or other organ of the body within and around the individual's body boundary at GPS locations. Everyone uses 
mobile phone within GPS location, but none can know its impact.

Methods: This impact identifies through ISNAH Experiment on cat and dog through application of processed wireless sensor networks at open activities eyes and GPS positions.

Results: This study represents the numbness with sudden pain due to misuse of wireless sensor networks towards an individual's body at light and dark environment. The research also focuses on the more effective enlarging causes of numbness in dark than light environment. These findings replicate the implication in numbness through operative treatment and recovery that the surgeons provide, which cannot improve efficiently due to abusing wireless sensor networks. The study also found the digitalized health systems are in risks to insecure advances sensor technology.

Conclusion: Systematic healthcare awareness is vital for management with modern technological device but such awareness is still below par, which is alarming to individual's good health. The study suggests future research trajectories of a new sophisticated alternative secure treatment approach to promote healthcare in the priority of Sustainable Development Goals 2030.

Keywords: Numbness; GPS Location; Body boundary; Sensor Networks; Environment.

\section{Introduction}

Nowadays numbness augments in legs or feet or lower part of the body in sudden among human beings [1-4]. Numbness of body is a silent sensor disease, which is numbed from the waist down to the legs $[5,6]$. Suddenly some male or females may feel numbness in their legs and feet or lower part of the body or entire body because of sitting / sleeping in a position that puts too much pressure on the nerves or reduces blood flow or lack of body electron movement [7-10]. However, continuing or unexplained numbness may be a mark of a causal medical condition [11-13]. Long-term numbness or a tingling feeling in the legs, feet, part of body or entire body may be because of conditions in several ways, such as multiple sclerosis, diabetes, peripheral artery disease, fibromyalgia or unwanted sensor networks [14-18]. A lack of pharmacological tools has delayed our understanding of the physiological mechanisms of causal tingling paresthesia. It may feel the sensation in the entire leg, below the knee, in different areas of foot or lower part of the body within a body boundary of the existing GPS locations [19-22]. From higher study research, the researcher finds new ideas of the reasons any person might experience numbness in the legs, feet or lower part of the body or in the full body suddenly numbness, along with identified symptoms, treatment with recovery systems $[17,23-26]$. The aim of the study is to find out the root causes of numbness through processed wireless sensor networks to solve with core challenges in worldwide public health security.

\section{Materials and Methods}

We conducted this research method at as $\mathrm{PhD}$ research work from October 2014 to October 2017 at the Universiti Malaysia Sarawak (UNIMAS), Malaysia. We connected the method with different parameters to enhance data collection, ISNAH Experiment, Specimens Tracking Process, Data Analysis and interpretation as below

\section{Data Collection}

All specimens housed in a room with controlled temperature $36.4^{\circ} \mathrm{C}$ in cat and $36.7^{\circ} \mathrm{C}$ in dog with breathing rates, respiration, blood pressure and feline body mass index.The experimental design randomly divided into three experimental groups with Body Mass Index: obese, normal and thin and observed the impact of wireless sensor networks towards pancreases among them in the light and dark environments. The study causes an integration of methods used in wireless sensor networks towards animals' body and identified its implication. This envisaged the research taking in matter-of-fact research elements to investigate issue hoisted in the study, primarily targeted at SMART devices like telematics' users towards specimens. Telematics is a smart device, comprises scanner, Global Positioning System (GPS) and Global Navigation Satellite System (GNSS). The fieldwork conducted in the studied area from January 2015 to January 2017.

\section{ISNAH Experiment}

Sensor technology comprises ISNAH Experiment. It implies the experiment on the Impact of Sensor Network on Animals and Human beings (ISNAH). The cyber trackers misuse the sensor technology to augment noncommunicable diseases among animals and human body. The study examined into two specimens, one is dog and another one is cat among 14 individuals for identification of this misuse application. These animals are available in the study area and suitable for experiment. The study selected sound health two species with Feline Body Mass Index (FBMI) and other following parameters as shown in (Table 1).

The experiment took on dark and light conditions. The specimens stayed in specific geographic location and put the individual inside the iron case (size: $\left.3.5^{\prime} \times 2^{\prime} \times 2.5^{\prime}\right)$. Then

Citation: Md Rahimullah Miah", , A A M Shazzadur Rahman², Mohammad Abdul Hannan ${ }^{3}$, Alamgir Adil Samdany ${ }^{4}$, Foujia Akhtar ${ }^{5}$, Md Sabbir Hossain ${ }^{6}$, S.A.M. Imran Hossain ${ }^{7}$, Md Shahariar Khan ${ }^{8}$, Md. Sher-E-Alam ${ }^{9}$, Jorin Tasnim Parisa ${ }^{10}$, Mohammad Basir Uddin ${ }^{11}$, Fuad Abdullah ${ }^{12}$, Chowdhury Shadman Shahriar ${ }^{13}$, Md Mehedi Hasan ${ }^{14}$, Alexander Kiew Sayok ${ }^{15}$, Ahi Sarok ${ }^{16}$, Mohammad Belal Uddin ${ }^{17}$, Motia Begum ${ }^{18}$, Jorin Tasnim Parisa ${ }^{19}$, Md Mokbul Hossain ${ }^{20}$, Mohammad Taimur Hossain Talukdar ${ }^{21}$, Shahriar Hussain Chowdhury ${ }^{22}$.Effect of Wireless Sensor Net- 2 works to Increasing Causes of Numbness Op Acc J Bio Sci \& Res 9(1)-2021 
Table 1: Two selected animals' specimens with Feline Body Mass Index (FBMI).

\begin{tabular}{|c|c|c|c|c|c|}
\hline Specimen & $\begin{array}{c}\text { Body } \\
\text { Temperature }\end{array}$ & $\begin{array}{c}\text { Respiration (per } \\
\text { minute) }\end{array}$ & $\begin{array}{c}\text { Blood Pressure } \\
\text { (mmHg) }\end{array}$ & FBMI & Breathing Rate \\
\hline Dog & $36.7^{0} \mathrm{C}$ & 25 & $122 / 180$ & 24.7 & $192 \mathrm{bpm}$ \\
\hline Cat & $36.4^{\circ} \mathrm{C}$ & 23 & $121 / 175$ & 24.2 & $210 \mathrm{bpm}$ \\
\hline
\end{tabular}

Moble Phone Laphce Deskliop, Electronic Denice

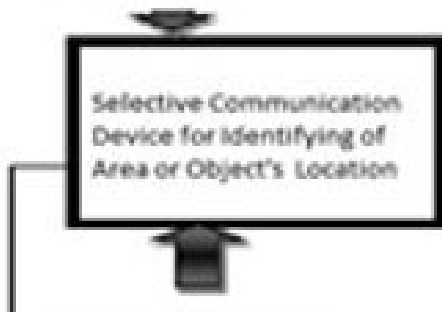

Usine Terminal based Software like Bio-lit, Bio-cache _oumete
Identification of Longtude. Latude and Ellipsoid height

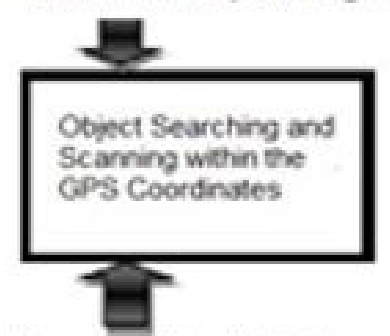

Measuring Cbject's Body Boundary and Scaling with Representative Fraction

\section{Dark Emwormental Ste} index and see Quality

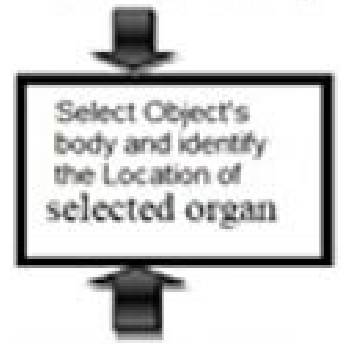

Ligh Environmertal Ste index and ste Qualty
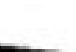

Using Globdi Posiboning Systems for Coordinates and Height
Time Series and Rieal time isferitier

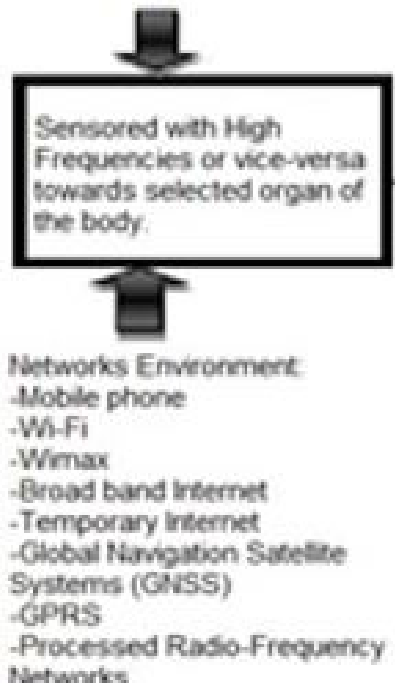
intworks

Active Open Eyes

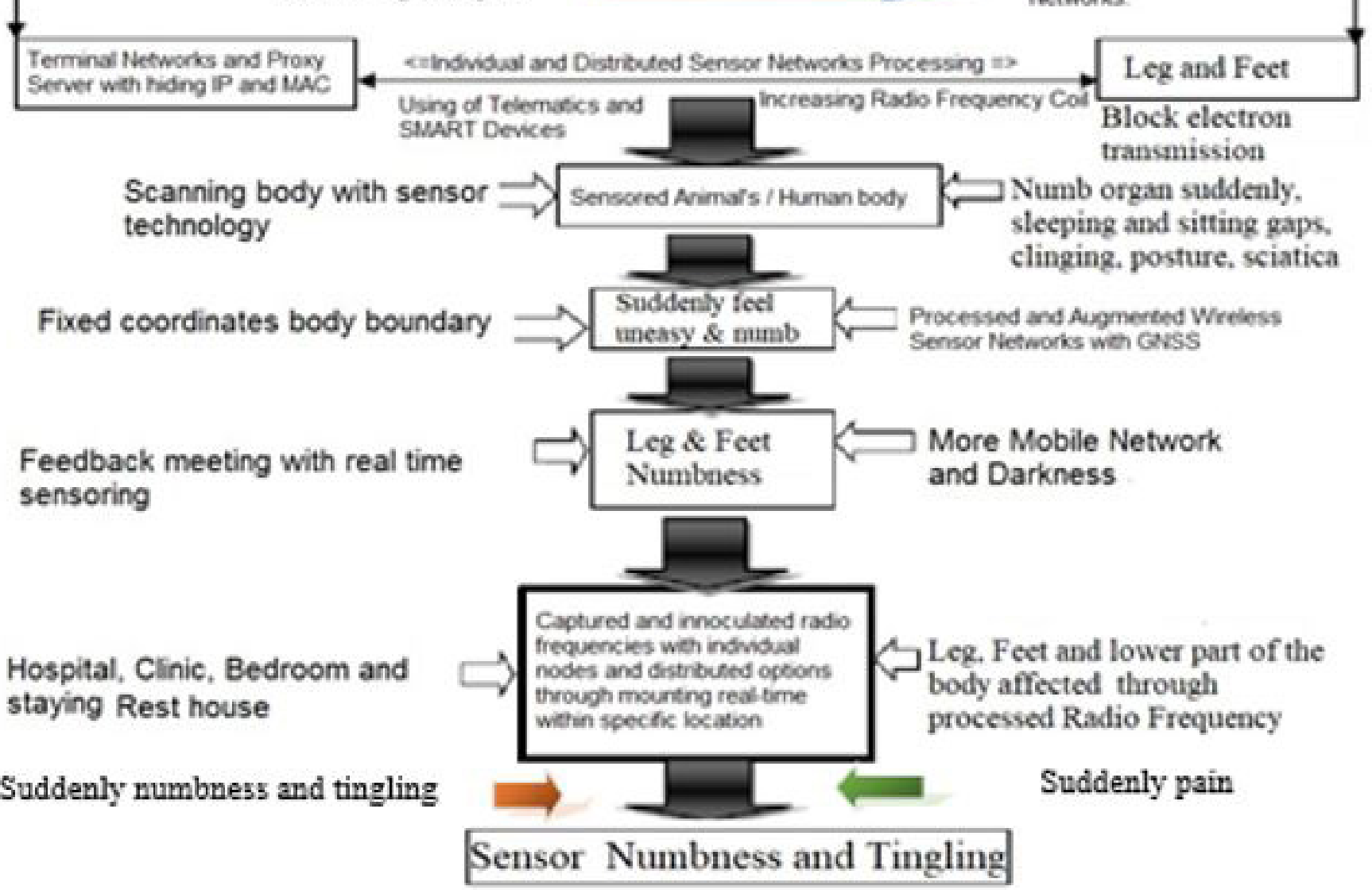

Figure 1: Numbness through Tracking with Processed Radio Frequency [76].

Citation: Md Rahimullah Miah" ${ }^{1 *}$, A A M Shazzadur Rahman², Mohammad Abdul Hannann ${ }^{3}$, Alamgir Adil Samdany ${ }^{4}$, Foujia Akhtar ${ }^{5}$, Md Sabbir Hossain ${ }^{6}$, S.A.M. Imran Hossain ${ }^{7}$, Md Shahariar Khan ${ }^{8}$, Md. Sher-E-Alam ${ }^{9}$, Jorin Tasnim Parisa10, Mohammad Basir Uddin ${ }^{11}$, Fuad Abdullah ${ }^{12}$ Chowdhury Shadman Shahriar ${ }^{13}$, Md Mehedi Hasan ${ }^{14}$, Alexander Kiew Sayok ${ }^{15}$, Ahi Sarok ${ }^{16}$, Mohammad Belal Uddin ${ }^{17}$, Motia Begum ${ }^{18}$, Jorin Tasnim Parisa ${ }^{19}$, Md Mokbul Hossain ${ }^{20}$, Mohammad Taimur Hossain Talukdar ${ }^{21}$, Shahriar Hussain Chowdhury ${ }^{22}$.Effect of Wireless Sensor Net- 3 works to Increasing Causes of Numbness Op Acc J Bio Sci \& Res 9(1)-2021 
measurement of individual's coordinates location includes longitude, latitude and ellipsoid height with GPS and GNSS identifiers.From the field observation, the Automated Radio Telemetry System is more effective in dark than light environment. For this purpose, the study was to examine the system with on smart cell phone, telematics device, iron cage and individual species separately. The dog and cat put into the iron cage with cell phones separately.

The experiment continued at five locations, viz.

1. Location A with light environments but no Wi-Fi,

2. Location B with dark and light environments including Wi-Fi,

3. Location $\mathrm{C}$ with dark and light environments including Wi-Fi,

4. Location $\mathrm{D}$ with light environments but no Wi-Fi,

5. Location E dark and light environments including Wi-Fi.

These experiments continued to identify the reflection of Automated Radio Telemetry System from Telematics device via cell phone towards animals at 09:00 p.m. to 6:00 a.m. from 1 January 2017 to 28 January 2017. The location of experiment settled the species with the temporal conditions through global positioning system. Although many important moments in animal's life are difficult to study because they are rare, cryptic or occur over large spatial or temporal scales. For the study of FBMI calculation, we used the study web calculator through using rib case circumference and length of the lower back leg from the knee to the ankle.

\section{Specimens Tracking Process}

Sensor networks track on animals and human beings, where contains in blood circulation and movement of electron. The ISNAH experiment interlinked electron through tracking process. This process included several steps which enhanced to fulfill the Sensored observation. The study was observed the physical conditions including non-communicable diseases of animals like diabetes affected by the telematics device through misapplication radio frequency through tracking process as shown in (Figure 1). Different stages of Tracking Process of Radio Frequency towards animals are listed as below:

1. Selective communication devices,

2. Searching object and scanning of individuals body organ,
3. Identify body organ and light and dark environment,

4. Sensored the specimens with high, normal and low radio frequency,

5. Observed and compared the specimens status,

6. Feedback meeting and illustrated the consequences at result and discussion.

\section{Data Analysis and Interpretation}

Quantitative and qualitative related bio-sensor data got through field observation, interviews, field surveys and ISNA experiment while we got secondary data from diverse sources. All general information regarding the occurrence of specimens, status and affected condition checked for accuracy from the unique sources and sources of information also verified. We collected information regarding the initiatives of the authority towards the geographic locations through relevant secondary information and field survey. The compiled and processed data involved in preparing data master sheet and assimilated into suitable systems used in the results and other segments consecutively. The data compiled and analyzed for presentation and interpretation using standard data analysis software like MS Office Suite 2019 and SPSS version 27.

Results

\section{occurring of Numbness with Sensor Technology}

Due to misuse of fluctuated radio frequencies within a GPS location, any animal or human beings suffers in numbness in actual time within specific radius of the individual's body boundary. The processed frequencies create the digital poisoning within the circumference of an individual's optical distance. Because of this, it blocked electron movement or blood circulation with poisoning in GPS location. If any person misuse the telematics or relevant sensor device towards he / she or both of them, they suffer in numbness at the poisoned location.

Suddenly or after a few moments at sitting or sleeping, a male or female's legs go numb temporarily because of their posture or staying in an existing environment. This numbness creates as a chronic or long-lasting in a specific of the body, which is almost always a sign of an underlying medical condition or physical structure. Suddenly causes of numbness include
a. fluctuated radio frequency,
b. posture,
c. sleeping gaps,

Citation: Md Rahimullah Miah 1,*, A A M Shazzadur Rahman², Mohammad Abdul Hannan ${ }^{3}$, Alamgir Adil Samdany ${ }^{4}$, Foujia Akhtar ${ }^{5}$, Md Sabbir Hossain ${ }^{6}$, S.A.M. Imran Hossain ${ }^{7}$, Md Shahariar Khan ${ }^{8}$, Md. Sher-E-Alam ${ }^{9}$, Jorin Tasnim Parisa ${ }^{10}$, Mohammad Basir Uddin $^{11}$, Fuad Abdullah ${ }^{12}$, Chowdhury Shadman Shahriar ${ }^{13}$, Md Mehedi Hasan ${ }^{14}$, Alexander Kiew Sayok ${ }^{15}$, Ahi Sarok ${ }^{16}$, Mohammad Belal Uddin ${ }^{17}$, Motia Begum ${ }^{18}$, Jorin Tasnim Parisa ${ }^{19}$, Md Mokbul Hossain ${ }^{20}$, Mohammad Taimur Hossain Talukdar ${ }^{21}$, Shahriar Hussain Chowdhury ${ }^{22}$.Effect of Wireless Sensor Net- 4 works to Increasing Causes of Numbness Op Acc J Bio Sci \& Res 9(1)-2021

DOI: 10.46718/JBGSR.2021.09.000217 
Table 2: Some reasons for numb legs, feet or lower part or whole body due to processed sensors.

\begin{tabular}{|c|c|}
\hline Reasons & Finding Characteristics \\
\hline $\begin{array}{c}\text { Fluctuated } \\
\text { Radio }\end{array}$ & $\begin{array}{c}\text { Optimum uses of radio frequency are suitable for body boundary. It is helpful to movement or straight of } \\
\text { the body or part of the body. But suddenly fluctuated sensor radio frequency is harmful to all living beings. } \\
\text { Any male or female can be affected in numbness due to misusing of fluctuated sensor radio frequency } \\
\text { within GPS locations. Besides, there are other causes in body numbness and tingling, posture, injury, } \\
\text { diabetes, lower back breakdown, sciatica irritation, Tarsal tunnel syndrome, Peripheral artery disease, } \\
\text { Tumors, Abnormal growth, Fibromyalgia, Multiple sclerosis and stroke. }\end{array}$ \\
\hline Others & $\begin{array}{r}\text { Sleeping, clinging and sitting gaps are also causes in numbness due to misusing wireless sensors. } \\
\hline\end{array}$ \\
\hline
\end{tabular}

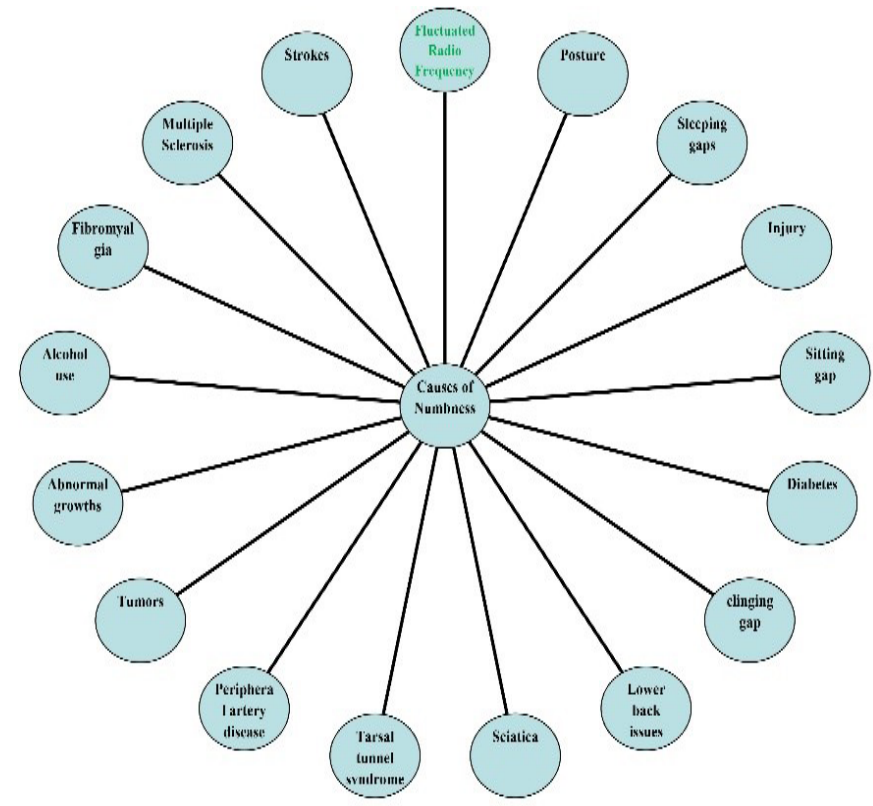

Figure 2: Causes of Numbness of the body or part of the body.

d. injury,

e. sitting gap,

f. diabetes,

g. clinging gap,

h. lower back issues,

i. sciatica,

j. tarsal tunnel syndrome,

k. carpal tunnel syndrome,

I. peripheral artery disease,

m. tumors,

n. abnormal growths,

o. fibromyalgia, p. multiple sclerosis,

q. stroke, and

r. alcohol use.

There are some specific symptoms for numb legs or feet or lower part of the body. Numbness is just one of the many symptoms associated with temporary and chronic numbness. Many people with numbness in their body organs experience additional symptoms at the same time or intermittingly including

i. tingling,

ii. burning,

iii. tickling,

iv. itching,

v. crawling feeling under the skin, which as shown in (Figure 2) (Table 2).

If an individual suffers in numbness, he/she can take some simple steps to protect his/her limbs, reducing discomfort and improve mobility. Many people believe it is a crippling and practicable part of growing old. But effects are changing through the expansion of innovative technology. Treatments are better with innovative technology due to open-closed eyes systems, which illustrated in discussion part. Plenty of aged-people are well with little in numbness owing to sensor technological awareness.

The study mentioned that he/she is sitting or sleeping at home or in the office. If he has a mobile phone or sensor device around him with open eyes, his location knew easily. Even if he doesn't have a mobile phone, we can know your location through laughing, crying, yawning, coughing, sneezing, talking, speaking, flattering, or being with open eyes. The distance between the various parts of individual's body knew through the telematics device around him, and

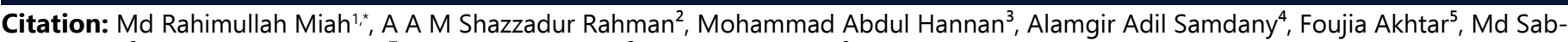
bir Hossain ${ }^{6}$, S.A.M. Imran Hossain ${ }^{7}$, Md Shahariar Khan ${ }^{8}$, Md. Sher-E-Alam ${ }^{9}$, Jorin Tasnim Parisa ${ }^{10}$, Mohammad Basir Uddin ${ }^{11}$, Fuad Abdullah ${ }^{12}$ Chowdhury Shadman Shahriar ${ }^{13}$, Md Mehedi Hasan ${ }^{14}$, Alexander Kiew Sayok ${ }^{15}$, Ahi Sarok ${ }^{16}$, Mohammad Belal Uddin ${ }^{17}$, Motia Begum ${ }^{18}$, Jorin Tasnim Parisa ${ }^{19}$, Md Mokbul Hossain ${ }^{20}$, Mohammad Taimur Hossain Talukdar ${ }^{21}$, Shahriar Hussain Chowdhury ${ }^{22}$.Effect of Wireless Sensor Net- 5 works to Increasing Causes of Numbness Op Acc J Bio Sci \& Res 9(1)-2021 


Suddenly causes of
Numbness:
-Fluctuated Radio Frequency
-Posture
-Sleeping gaps
-Injury
-Sitting gap
-Diabetes
-Clinging gap
-Lower back issues
-Sciatica
-Tarsal tunnel syndrome
-Peripheral Artery Disease
-Tumors
-Abnormal growths
-Fibromyalgia
-Multiple sclerosis
-Stroke
-Hotdrinks use

\section{Suddenly causes of}

-Fluctuated Radio Frequency

-Posture

-Sleeping gaps

-Injury

-Sitting gap

-Diabetes

-Clinging gap

-Lower back issues

-Sciatica

-Tarsal tunnel syndrome

-Peripheral Artery Disease

-Tumors

-Abnormal growths

-Fibromyalgia

-Multiple sclerosis

-Hotdrinks use
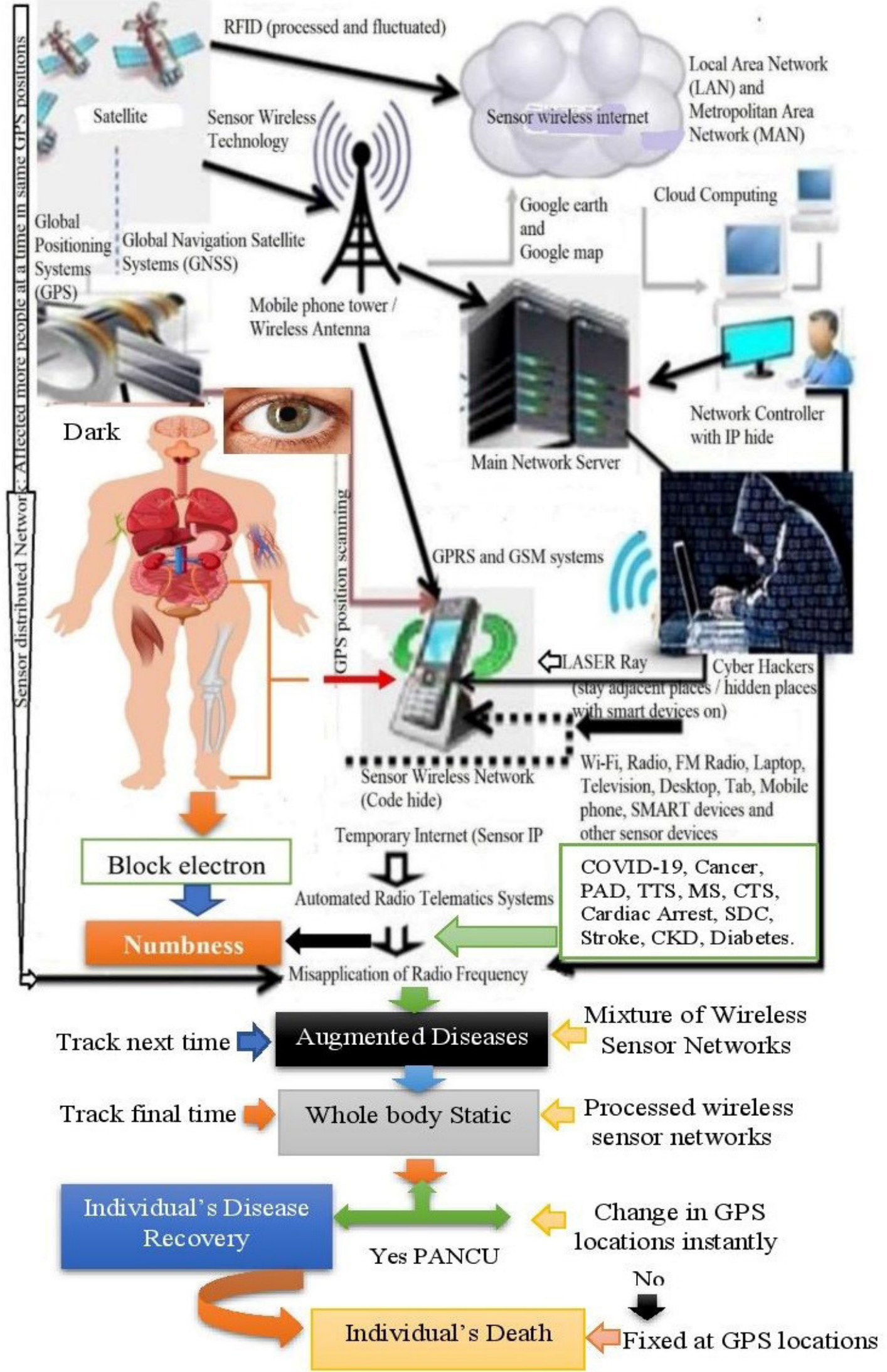

Figure 3: Fluctuated Radio Frequency due to causes of numbness legs.

Citation: Md Rahimullah Miah", , A A M Shazzadur Rahman², Mohammad Abdul Hannan ${ }^{3}$, Alamgir Adil Samdany ${ }^{4}$, Foujia Akhtar ${ }^{5}$, Md Sab- $^{2}$ bir Hossain 6 , S.A.M. Imran Hossain ${ }^{7}$, Md Shahariar Khan ${ }^{8}$, Md. Sher-E-Alam ${ }^{9}$, Jorin Tasnim Parisa' ${ }^{10}$, Mohammad Basir Uddin ${ }^{11}$, Fuad Abdullah ${ }^{12}$, Chowdhury Shadman Shahriar ${ }^{13}$, Md Mehedi Hasan ${ }^{14}$, Alexander Kiew Sayok ${ }^{15}$, Ahi Sarok ${ }^{16}$, Mohammad Belal Uddin ${ }^{17}$, Motia Begum ${ }^{18}$, Jorin Tasnim Parisa ${ }^{19}$, Md Mokbul Hossain ${ }^{20}$, Mohammad Taimur Hossain Talukdar ${ }^{21}$, Shahriar Hussain Chowdhury ${ }^{22}$.Effect of Wireless Sensor Net- 6 works to Increasing Causes of Numbness Op Acc J Bio Sci \& Res 9(1)-2021 
then digital scanning does with software like Computed Tomographic scan or Magnetic Resonance Imaging, the individual's hand, legs or lower part of the body or whole body feel numb suddenly. Remote sensing device then applied the fluctuated-frequencies with electromagnetic force to the connective tissue in the area via telematics. After the few moments, fluctuated mobile sensor particles in the blood vessel contracts, the blood flow stops and the connective tissue becomes useless, then the leg or hand or lower part of the body becomes in numbness, which as shown in (Figure 3). In light environment, numbness occurs in 25 minutes and in a dark environment, it takes 12 minutes. However, optimum uses of radio frequency are suitable for body boundary. It is helpful to movement or straight of the body or part of the body. But suddenly fluctuated sensor radio frequency is harmful to all living beings. It can affect any male or female in numbness due to misuse of fluctuated sensor radio frequency within GPS locations.

\section{Discussion}

Sensor technology is a blessing to all generations for sound health in a sound mind. But some cyber hackers are misusing the processed radio frequency with sensor technological devices and optical sights within GPS locations [27-30]. They create abnormal situation towards an individual's body within the body boundary area. Then he/she affects in numbness either temporary or long-lasting [31-34]. Many people say their legs have "fallen asleep", which is termed in medically as transient paresthesia [3540]. Habits that can cause the body or part of body to fall asleep including

i. crossing the legs for too long,

ii. sitting or kneeling for long periods,

iii. sitting on the feet,

iv. wearing pants, shoes, socks, gloves that are too tight [41-45].

Most people with fibromyalgia experience a variety of symptoms including

a. stiffness and soreness for no apparent reason, especially in the morning or after sleeping,

b. chronic exhaustion,

c. memory problems and difficulty thinking clearly, sometimes called fibro-fog,

d. restless leg syndrome [46-50].

Almost everyone with fibromyalgia suffers symptoms in over one part of their body for at least 3 months at a time. Any other symptoms do not accompany if numbness in the legs and feet or is not long term, it is unlikely to be caused by fibromyalgia. The tarsal tunnel is a narrow space on the inside of the ankle $[51,52]$. Male or female with tarsal tunnel syndrome felt numbness, burning, tingling, and shooting pain in their ankles, heel and feet. It linked this type of nerve damage to reduced levels of B vitamins, such as B-1 (thiamine), B-9 (folate), and B-12, which is caused by excessive alcohol intake [53-56]. The legs are one of the most common parts of the body affected by Peripheral Artery Disease (PAD) [57-59]. Most people with PAD experience pain and cramping in their entire body or part of the body, or in their legs and hips, when they are walking or going upstairs [60-65]. Some are with PAD also experiences leg numbness and weakness. Symptoms of PAD typically go away after a few minutes of rest [66-70]. However, the mentioned causes occurred by the missing of sensor technology, which as shown in (Figure 4). Though they may occur these as usual, either certain conditions. The numbness can cause problems correlated to sensing, feeling, and moving of the body or part of the body [53].

Some patients suffer from the symptoms as numbness in their hands or feet. After lying on one side of the bed at night for a while, the hands and feet on that side feel numb. Because of these reasons, it is difficult to sleep at night. Sometimes, if the patients hold something in their hands for some time, their hands feel numb. After a while they can't hold on anymore. The doctor observed the patients' history that they couldn't even hold the mobile phone in their ears for long while talking on the mobile phones [48]. Many wonders why this could happen, which needs to find the root causes. Because of this problem, the blood circulation in hands and feet is less than normal [71]. Then the pain occurs due to fluctuated pressure on the cervical spine or neck and lumber spine, or the nerves in the waist [56]. The numbness also happens in some diseases including cervical spondylosis, carpal tunnel syndrome, lumber spondylosis, varicose veins, peripheral neuropathy, diabetic neuropathy and motor-neuron disease. Due to lack of vitamins or minerals, the patients suffer in numbness. But the numbness occurs suddenly, the study takes the instant time towards patients' numbness seriously due to misuse of fluctuated radio frequency. Because of which the numbness later becomes severe, it becomes difficult to get rid of the disease. Therefore, if such symptoms occur, it is necessary to take the advice of a specialist without delay and take treatment for recovery after diagnosing the cause [72]. Occasionally the limbs become numb, which is a symptom of some sensor diseases through misapplications of sensor

Citation: Md Rahimullah Miah ${ }^{1, *}$, A A M Shazzadur Rahman², Mohammad Abdul Hannan ${ }^{3}$, Alamgir Adil Samdany ${ }^{4}$, Foujia Akhtar ${ }^{5}$, Md Sabbir Hossain ${ }^{6}$, S.A.M. Imran Hossain ${ }^{7}$, Md Shahariar Khan ${ }^{8}$, Md. Sher-E-Alam ${ }^{9}$, Jorin Tasnim Parisa ${ }^{10}$, Mohammad Basir Uddin ${ }^{11}$, Fuad Abdullah ${ }^{12}$, Chowdhury Shadman Shahriar ${ }^{13}$, Md Mehedi Hasan ${ }^{14}$, Alexander Kiew Sayok ${ }^{15}$, Ahi Sarok ${ }^{16}$, Mohammad Belal Uddin ${ }^{17}$, Motia Begum ${ }^{18}$, Jorin Tasnim Parisa ${ }^{19}$, Md Mokbul Hossain ${ }^{20}$, Mohammad Taimur Hossain Talukdar ${ }^{21}$, Shahriar Hussain Chowdhury ${ }^{22}$.Effect of Wireless Sensor Net- 7 works to Increasing Causes of Numbness Op Acc J Bio Sci \& Res 9(1)-2021 


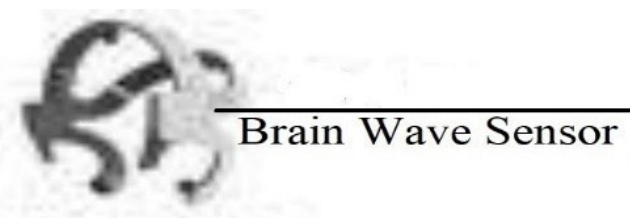

\section{Neuromotor Sensor}

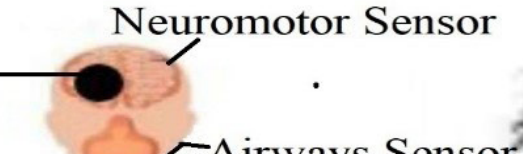

Neck Wave Sensor

Airways Sensor
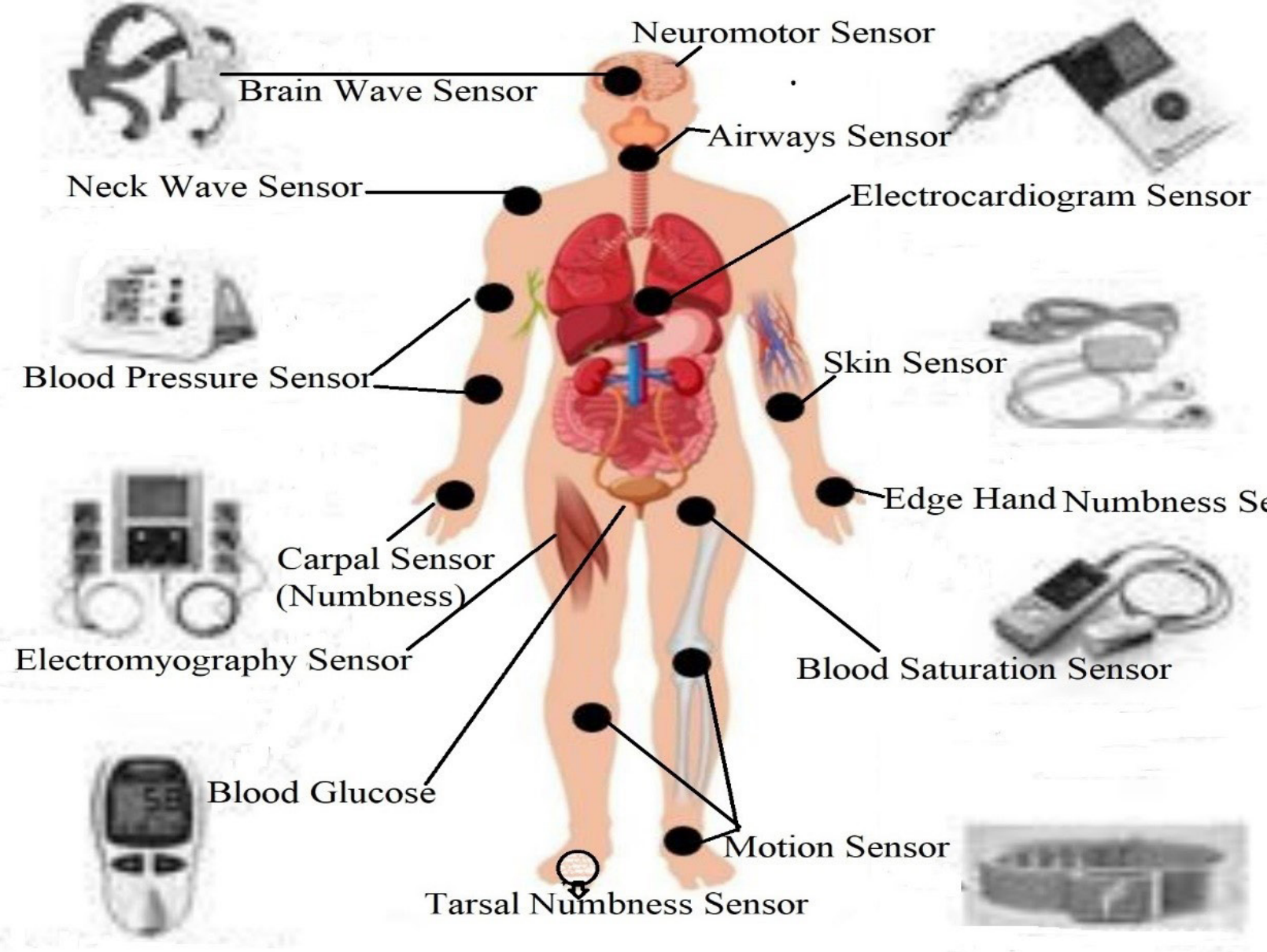

Figure 4: Misuse of Processed Wireless Sensor Networks [76].

technology within GPS locations.

\section{Treatment}

The proper treatment for numb legs, feet or part of the body depends entirely on the cause.

\section{Medication}

Medical options are for long-term numbness in the legs, feet or other organs of the body:

Antidepressants: Some antidepressants, such as duloxetine and milnacipran, have approved to treat fibromyalgia.

Corticosteroids: Some corticosteroids can help reduce chronic inflammation and numbness associated with conditions such as MS.

Gabapentin and pregabalin: Medications that block or change nerve signaling may help reduce numbness associated with conditions such as fibromyalgia, MS, and diabetic neuropathy.

\section{Home-based Remedies}

Home remedies that may help to relieve uncomfortable numbness in the legs, feet or lower part of the body through following parameters [73-76], which as shown in (Table 3x).

\section{Challenges}

At present, developing countries have no reliable sensor data despite substantial investments in digital health systems due to lack of sensor security $[49,50]$. The crowdsourcing data about providers, facilities and health measures is likely to grow more individuals with wireless sensor networks in risks. Artificial health intelligence and internet of everything use for better care and diagnosis, but these are expensive innovative technologies.

\section{Conclusion}

In conclusion, the study identifies the numbness limbs or part of the body within GPS locations because of the fluctuated radio frequencies. Based on this research,

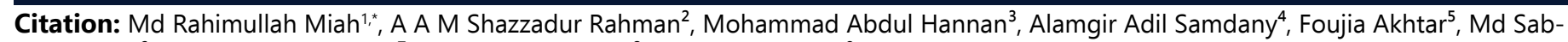
bir Hossain ${ }^{6}$, S.A.M. Imran Hossain ${ }^{7}$, Md Shahariar Khan ${ }^{8}$, Md. Sher-E-Alam ${ }^{9}$, Jorin Tasnim Parisa ${ }^{10}$, Mohammad Basir Uddin ${ }^{11}$, Fuad Abdullah ${ }^{12}$, Chowdhury Shadman Shahriar ${ }^{13}$, Md Mehedi Hasan ${ }^{14}$, Alexander Kiew Sayok ${ }^{15}$, Ahi Sarok ${ }^{16}$, Mohammad Belal Uddin ${ }^{17}$, Motia Begum ${ }^{18}$, Jorin Tasnim Parisa ${ }^{19}$, Md Mokbul Hossain ${ }^{20}$, Mohammad Taimur Hossain Talukdar ${ }^{21}$, Shahriar Hussain Chowdhury ${ }^{22}$.Effect of Wireless Sensor Net- 8 works to Increasing Causes of Numbness Op Acc J Bio Sci \& Res 9(1)-2021 
Table 3: Home-based remedy systems for recovery of legs or feet numb.

\begin{tabular}{|c|c|}
\hline Parameters & Remedies \\
\hline Wearing Sunglasses & $\begin{array}{l}\text { Sunglasses can control unwanted radio frequencies that can recvover numbness in light } \\
\text { environment. }\end{array}$ \\
\hline PANCU & Set up Personal Area Network Control Unit (PANCU) at fixed GPS location. \\
\hline Taking sensed food & $\begin{array}{l}\text { Sensor food creates sense with blood connection for development of immune system to redude } \\
\text { numbness. Sensed foods like garlic, peeper, black cumin... etc. }\end{array}$ \\
\hline Using Ice & $\begin{array}{l}\text { Ice can help reduce swelling that can put pressure on nerves. If he/she applies cold compresses } \\
\text { or wrapped icepacks to numb legs and feet for 10-12 minutes at a time several times daily. }\end{array}$ \\
\hline Rest & $\begin{array}{c}\text { Many of the conditions that cause leg and foot numbness, such as nerve pressure, improve with } \\
\text { rest. }\end{array}$ \\
\hline Massage & Massaging numb legs and feet helps improve blood flow and may reduce symptoms. \\
\hline Heat & $\begin{array}{l}\text { Heat can sometimes help loosen stiff, sore, or tense muscles that can put pressure on nerves } \\
\text { and cause numbness. However, avoid overheating numb legs and feet, as this may or worsen } \\
\text { inflammation and cause pain and numbness. }\end{array}$ \\
\hline Epsom salt baths & $\begin{array}{l}\text { Epsom salts contain magnesium, a compound known to increase blood flow and circulation. } \\
\text { Epsom salts are available for purchase online. }\end{array}$ \\
\hline Exercise & $\begin{array}{l}\text { A lack of proper exercise can weaken the heart and blood vessels, reducing their ability to pump } \\
\text { blood to the lower limbs. Activities such as yoga, pilates and regular exercise can promote blood } \\
\text { flow and reduce chronic inflammation or pain. }\end{array}$ \\
\hline Supportive devices & $\begin{array}{l}\text { Braces and specially designed footwear can help reduce nerve pressure caused by conditions } \\
\text { such as injury, tarsal tunnel syndrome, or flat_feet. }\end{array}$ \\
\hline Sleep & $\begin{array}{l}\text { Many of the chronic conditions associated with legs and feet numbness are known to worsen } \\
\text { with a lack of proper sleep. Sound sleep can help recovery numbness. }\end{array}$ \\
\hline Mental techniques & $\begin{array}{l}\text { People with conditions that cause chronic numbness, such as MS and fibromyalgia, should try to } \\
\text { focus on the fact that the periods of numbness are often short-lived and go away on their own. }\end{array}$ \\
\hline Stress reduction & $\begin{array}{l}\text { Stress tends to make the symptoms of vital nervous system disorders worse, which reduce } \\
\text { numbness through its management. }\end{array}$ \\
\hline Inspection & $\begin{array}{l}\mathrm{He} / \text { she makes sure to inspect his/her feet for sores and blisters. This is important regardless } \\
\text { of the cause of numb or tingling legs or feet. Numbness can prevent them from feeling injuries, } \\
\text { which can lead to infections that could spread to other areas of the body. }\end{array}$ \\
\hline Balanced diet & $\begin{array}{l}\text { Malnutrition, especially vitamin B deficiencies, can cause nerve damage leading to numbness. } \\
\text { Getting enough vitamins and other nutrients can also reduce chronic inflammation and pain, } \\
\text { which can cause numbness. }\end{array}$ \\
\hline Bracing & $\begin{array}{l}\text { For people experiencing too much pressure on the nerves, braces can help to relieve that } \\
\text { pressure, and any subsequent pain and numbness. Supportive shoes can also help. }\end{array}$ \\
\hline Avoidance hotdrinks & $\begin{array}{l}\text { Alcohol contains toxins that can cause nerve damage and numbness. Alcohol also usually makes } \\
\text { the symptoms of chronic pain and inflammatory conditions worse and can even cause flare-ups } \\
\text { of symptoms. }\end{array}$ \\
\hline
\end{tabular}

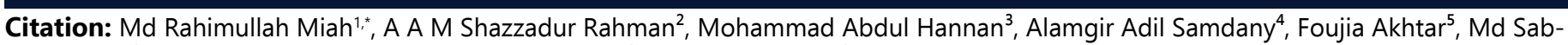
bir Hossain ${ }^{6}$, S.A.M. Imran Hossain ${ }^{7}$, Md Shahariar Khan ${ }^{8}$, Md. Sher-E-Alam ${ }^{9}$, Jorin Tasnim Parisa ${ }^{10}$, Mohammad Basir Uddin ${ }^{11}$, Fuad Abdullah ${ }^{12}$, Chowdhury Shadman Shahriar ${ }^{13}$, Md Mehedi Hasan ${ }^{14}$, Alexander Kiew Sayok ${ }^{15}$, Ahi Sarok ${ }^{16}$, Mohammad Belal Uddin ${ }^{17}$, Motia Begum ${ }^{18}$, Jorin Tasnim Parisa ${ }^{19}$, Md Mokbul Hossain ${ }^{20}$, Mohammad Taimur Hossain Talukdar ${ }^{21}$, Shahriar Hussain Chowdhury ${ }^{22}$.Effect of Wireless Sensor Net- 9 works to Increasing Causes of Numbness Op Acc J Bio Sci \& Res 9(1)-2021

DOI: 10.46718/JBGSR.2021.09.000217 
human beings and animals are not secure due to misuse of processed frequencies within body boundary wireless sensor networks in the existing environment. However, the study has attempted to improve a complete scenario of the speeding up causes of numbness in hands, feet, lower part of the body or complete body due to disseminating the fluctuated, homogenous and processed wireless sensor particles. The findings of this study obviously show for sensor network security and dynamic health policy towards present and rationalized generations. Everyone stays at optical sight with body boundary and innovative technology, but none can aware of its security systems. So, policy-makers, health experts and sensor technologists should develop a dynamic, secure health system in the future.

\section{Declarations}

\section{Funding}

This research work is a part of $\mathrm{PhD}$ research, which was funded by the Zamalah Postgraduate Scholarship of Universiti Malaysia Sarawak (UNIMAS), Kota Samarahan, Sarawak, Malaysia and also sponsored by the Information and Communication Technology Division (ICTD), Dhaka, Ministry of Posts, Telecommunication and Information Technology, Government of People's Republic of Bangladesh. The funders had no role in the design of the research, in data collection, analyses or final interpretation of data, in the writings of the manuscript, or in the decision to publish the findings.

\section{Data Availability}

The data are being used to support the findings of this research work are available from the corresponding author upon request.

\section{Competing Interests}

The authors declare no potential conflict of interests in this research work.

\section{Acknowledgements}

The authors acknowledged the authority of Universiti of Malaysia Sarawak (UNIMAS), Sarawak, Malaysia for providing the Zamalah Postgraduate Scholarship for the completion of the PhD degree. The authors are also grateful to the authority of the Information and Communication Technology Division (ICTD), Ministry of Posts, Telecommunication and Information Technology, Government of People's Republic of Bangladesh, for a PhD Fellowship during the higher study in Malaysia. The authors acknowledged the Authority of Northeast Medical Pvt. Limited, Sylhet, Bangladesh for kind supports.

\section{Author's Contributions}

MRM designed the study. MRM wrote the first draft of the manuscript with other co-authors ASR, MSK, AAS, MAH, SHC and AKS reviewing and amending the initial draft. AKS was the main supervisor of PhD thesis. All authors read and approved the final version of the manuscript.

\section{References}

1. Nall R (2019) Why Are My Limbs Numb? Health line.

2. Nall R (2018) Numbness of Foot. Health Line.

3. Zamir MA, Raoof J (2019) Tingling and numbness in the arm. BMJ.

4. Cooper G (2019) Leg Pain and Numbness: What Might These Symptoms Mean? 2019. SPINE-health.

5. Mayoclinic (2021) Numbness in hands.

6. Huizen, J (2020) Why my legs and feet numb? Medical News Today.

7. Shiel WC (2021) Numbness Toes: Symptoms and Signs. Medicine Net.

8. Weaver CH (2020) Neuropathy (Numbness and Tingling)- How is it Prevented and Treated? Cancer Connect.

9. JOSPT (2019) Carpal Tunnel Syndrome: Treating Hand Pain and Numbness. Journal of Orthopaedic \& Sports Physical Therapy 49(5): 361.

10. Inoue S, Ikeuchi $\mathrm{M}$, Okumura $\mathrm{K}$, Nakamura $\mathrm{M}$, Kawakami $\mathrm{C}$, et al. (2013) Health Survey of Numbness/Pain and Its Associated Factors in Kotohira, Japan. PLoS ONE 8(4): e60079.

11. Taxonomy ITFo (1994) Part III: Pain Terms: A Current List with Definitions and Notes on Usage. In: Merskey H, Bogduk N, editors. Classification of Chronic Pain. 2 ed. Seattle: IASP Press 209-214.

12. Todor DR, Mu HT, Milhorat TH (2000) Pain and syringomyelia: a review. Neurosurg Focus 8: E11.

13. Attal N, Bouhassira D (2006) Chapter 47 Pain in syringomyelia/ bulbia. Handb Clin Neurol 81: 705-713.

14. Robert R, Perrouin-Verbe B, Albert T, Bussel B, Hamel O (2009) Chronic neuropathic pain in spinal cord injured patients: what is the effectiveness of surgical treatments excluding central neurostimulations? Ann Phys Rehabil Med 52: 194-202.

15. Chang MH, Liao KK, Cheung SC, Kong KW, Chang SP (1992) Numb, clumsy hands and tactile agnosia secondary to high cervical spondylotic myelopathy: a clinical and electrophysiological correlation. Acta Neurol Scand 86: 622-625.

16. Lucchetta M, Pazzaglia C, Padua L, Briani C (2011) Exploring neuropathic symptoms in a large cohort of Italian patients with different peripheral nervous system diseases. Neurol Sci 32: 423426.

17. Vogt MT, Cawthon PM, Kang JD, Donaldson WF, Cauley JA, et al. (2006) Prevalence of symptoms of cervical and lumbar stenosis among participants in the Osteoporotic Fractures in Men Study. Spine 31: 1445.

18. Hicks GE, Gaines JM, Shardell M, Simonsick EM (2008) Associations of back and leg pain with health status and functional capacity of older adults: Findings from the retirement community back pain study. Arthritis Care \& Research 59: 1306-1313.

19. Young WF (2000) Cervical spondylotic myelopathy: a common cause of spinal cord dysfunction in older persons. American family physician 62: 1064.

20. Chittleborough CR, Baldock KL, Taylor AW, Phillips PJ (2006) Health status assessed by the SF-36 along the diabetes continuum in an Australian population. Qual Life Res 15: 687-694.

21. Hayden JA, van Tulder MW, Tomlinson G (2005) Systematic review:

Citation: Md Rahimullah Miah ${ }^{1, *}$, A A M Shazzadur Rahman², Mohammad Abdul Hannan ${ }^{3}$, Alamgir Adil Samdany ${ }^{4}$, Foujia Akhtar ${ }^{5}$, Md Sabbir Hossain ${ }^{6}$, S.A.M. Imran Hossain ${ }^{7}$, Md Shahariar Khan ${ }^{8}$, Md. Sher-E-Alam ${ }^{9}$, Jorin Tasnim Parisa ${ }^{10}$, Mohammad Basir Uddin ${ }^{11}$, Fuad Abdullah ${ }^{12}$, Chowdhury Shadman Shahriar ${ }^{13}$, Md Mehedi Hasan ${ }^{14}$, Alexander Kiew Sayok ${ }^{15}$, Ahi Sarok ${ }^{16}$, Mohammad Belal Uddin ${ }^{17}$, Motia Begum ${ }^{18}$, Jorin Tasnim Parisa ${ }^{19}$, Md Mokbul Hossain ${ }^{20}$, Mohammad Taimur Hossain Talukdar ${ }^{21}$, Shahriar Hussain Chowdhury ${ }^{22}$.Effect of Wireless Sensor Net-10 works to Increasing Causes of Numbness Op Acc J Bio Sci \& Res 9(1)-2021 
strategies for using exercise therapy to improve outcomes in chronic low back pain. Ann Intern Med 142: 776-785.

22. Bigbee A, Hoang T, Havton L (2007) At-level neuropathic pain is induced by lumbosacral ventral root avulsion injury and ameliorated by root reimplantation into the spinal cord. Experimental Neurology 204: 273-282.

23. Wieseler J, Ellis AL, McFadden A, Brown K, Starnes C, et al. (2010) Below level central pain induced by discrete dorsal spinal cord injury. Journal of neurotrauma 27: 1697-1707.

24. Defrin R, Ohry A, Blumen N, Urca G (2001) Characterization of chronic pain and somatosensory function in spinal cord injury subjects. Pain 89: 253-263.

25. Weng HR, Lee J, Lenz F, Schwartz A, Vierck C, et al. (2000) Functional plasticity in primate somatosensory thalamus following chronic lesion of the ventral lateral spinal cord. Neuroscience 101: 393-401.

26. Finnerup NB, Baastrup C (2012) Spinal Cord Injury Pain: Mechanisms and Management. Current pain and headache reports $1-10$.

27. Wollaars MM, Post MWM, van Asbeck FWA, Brand N (2007) Spinal cord injury pain: the influence of psychologic factors and impact on quality of life. The Clinical journal of pain 23: 383.

28. Whitlock J (2019) Numbness and Tingling after Surgery. Very Well Health.

29. Palmer KT (2011) Carpal tunnel syndrome: the role of occupational factors. Best Pract Res Clin Rheumatol 25(1):15-29.

30. Su YK, Wang JH, Hsieh SY, Liu XZ, Lam CF, et al. (2018) Incidence and risk factors for postoperative lingual neuropraxia following airway instrumentation: A retrospective matched case-control study. PLoS ONE 13(1): e0190589.

31. Neal JM, Bernards CM, Hadzic A, Hebl JR, Hogan QH, et al. (2008) ASRA Practice Advisory on Neurologic Complications in Regional Anesthesia and Pain Medicine. Reg Anesth Pain Med 33(5): 404415.

32. Reda B, Wong I (2018) Postoperative Numbness: A Survey of Patients After Hip Arthroscopic Surgery. Orthop J Sports Med 6(5): 2325967118771535.

33. Kuponiyi O, Alleemudder DI, Latunde-Dada A, Eedarapalli P (2014) Nerve injuries associated with gynaecological surgery. The Obstetrician \& Gynaecologist 16: 29-36.

34. Azizzadeh B, Mashkevich G (2009) Nerve injuries and treatment in facial cosmetic surgery. Oral Maxillofac Surg Clin North Am 21(1): 23-29.

35. Woessner H, Vibhute P, Barrett K (2012) Acute loss of bladder control in a stroke of the frontal cortex. Neurohospitalist 2(4): 129131.

36. Tzermpos FH, Cocos A, Kleftogiannis M, Zarakas M, Iatrou I (2012) Transient delayed facial nerve palsy after inferior alveolar nerve block anesthesia. Anesth Prog 59(1) :22-27.

37. Borsook D, Kussman BD, George E, Becerra LR, Burke DW (2013) Surgically induced neuropathic pain: understanding the perioperative process. Ann Surg 257(3): 403-412.

38. Neofect (2021) Are There Treatments For Numbness After a Stroke?

39. Hoffman H (2018) How to Combat Numbness After Stroke. SAEBO.

40. FlintRehab (2019) Numbness After Stroke: How Long It Lasts \& Steps for Recovery. Flint Rehabilitation.

41. UPMC (2021) What Is Numbness or Weakness? Numbness and Weakness. UPMC.

42. Haugen AJ, Grøvle L, Brox JI, Natvig B, Keller A, et al. (2011) Estimates of success in patients with sciatica due to lumbar disc herniation depend upon outcome measure. Eur Spine J 20: 1669-
1675.

43. Sakakibara H, Miyao M, Kondo T, Furuta M, Yamada S, et al. (1989) Analysis of subjective symptoms of coldness and numbness in the upper and lower limbs among patients with vibration syndrome. Sangyo Igaku 31(4): 196-202.

44. DU (2021) Disorders of the Nervous system - Reeves \& Swenson: Chapter 13 - Evaluation of the patient with numbness. Dartmouth University.

45. NINDS (2021) Trigeminal Neuralgia Fact Sheet.

46. Orthoinfo (2021) Carpal Tunnel Syndrome.

47. Levin MC (2019) Numbness. College of Medicine, University of Saskatchewan.

48. Ali MY (2020) Why do the limbs feel numb? Broadcasting at NTV, Bangladesh.

49. Wyber R, Vaillancourt S, Perry W, Mannava P, Folaranmi T, et al. (2015) Big data in global health: improving health in lowand middleincome countries. WHO.

50. Bram JT, Warwick-Clark B, Obeysekar E, Mehta K (2015) Utilization and monetization of healthcare data in developing countries. Big Data 3(2): 59-66.

51. Versel N (2012) Wireless shoe inserts senses foot numbness that can lead to diabetic ulcers, amputation.

52. Lennertz RC, Tsunozaki M, Bautista DM, Stucky CL (2010) Physiological Basis of Tingling Paresthesia Evokedby Hydroxy-Sanshool. Journal of Neuroscience 30(12): 4353-4361.

53. Cancer Editorial Board (2018) Nerve Problems of Neuropathy. Cancer.Net Editorial Board 10: 1-2.

54. Huizen J (2020) Why are my legs and feet numb?

55. Jensen TS, Albert HB, Sorensen JS, Manniche C, Leboeuf-Yde C (2007) Magnetic resonance imaging findings as predictors of clinical outcome in patients with sciatica receiving active conservative treatment. Journal Manipulative Physiol Ther 30: 98-108.

56. Weinstein JN, Tosteson TD, Lurie JD, Tosteson AN, Hanscom B, et al. (2006) Surgical vs nonoperative treatment for lumbar disk herniation: the Spine Patient Outcomes Research Trial (SPORT): a randomized trial. JAMA 296: 2441-2450.

57. Youssef M, Mansour T, Abdelsalam HA (2016) The relationship between mobile phone use and ear Problems among medical students. Biomedical Research 27(4): 1251-1254.

58. Kucer N, Pamukcu T (2013) Self-reported symptoms associatedwith exposure to electromagnetic fields: a questionnairestudy. Electromagnet Biol Med 3: 1-4.

59. Merlo LJ, Stone AM, Bibbey A (2013) Measuring problematic mobile phone use: Development and preliminarypsychometric properties of the PUMP scale. J addiction 2013: 1- 7.

60. Maier M (2002) The health hazards of mobile phones. BritishMedical Journal 320: 1288-1289.

61. Meo SA, Al-Drees AM (2005) Mobile phone related-hazards andsubjective hearing and vision symptoms in the Saudipopulation. Int J Occup Med Environ Health 18: 53-57.

62. Schuz J, Waldemar G, Olsen J (2009) Risks for Central NervousSystem Diseases among Mobile Phone Subscribers: A Danish Retrospective Cohort Study. PLoS One 4: e4389.

63. Lonn S, Ahlbom A, Hall P, FeychtingM (2005) Long-TermMobile Phone Use and Brain Tumour Risk. American Journal of Epidemiology 161: 526-535.

64. Galeev AL (2000) The effects of microwave radiation frommobile telephones on humans and animals. NeurosciBehav Physiol 30: 187194.

65. Das S, Chakraborty S, Mahanta B (2017) A study on the effect of prolonged mobile phone use on pure tone audiometry thresholds

Citation: Md Rahimullah Miah ${ }^{1, *}$, A A M Shazzadur Rahman², Mohammad Abdul Hannan ${ }^{3}$, Alamgir Adil Samdany ${ }^{4}$, Foujia Akhtar ${ }^{5}$, Md Sabbir Hossain ${ }^{6}$, S.A.M. Imran Hossain ${ }^{7}$, Md Shahariar Khan ${ }^{8}$, Md. Sher-E-Alam ${ }^{9}$, Jorin Tasnim Parisa ${ }^{10}$, Mohammad Basir Uddin ${ }^{11}$, Fuad Abdullah ${ }^{12}$, Chowdhury Shadman Shahriar ${ }^{13}$, Md Mehedi Hasan ${ }^{14}$, Alexander Kiew Sayok ${ }^{15}$, Ahi Sarok ${ }^{16}$, Mohammad Belal Uddin ${ }^{17}$, Motia Begum ${ }^{18}$, Jorin Tasnim Parisa ${ }^{19}$, Md Mokbul Hossain ${ }^{20}$, Mohammad Taimur Hossain Talukdar ${ }^{21}$, Shahriar Hussain Chowdhury ${ }^{22}$.Effect of Wireless Sensor Net-11 works to Increasing Causes of Numbness Op Acc J Bio Sci \& Res 9(1)-2021 
of medical students of Sikkim. Journal of Postgrad Medicine 63(4): 221-225.

66. Yu WT, Choi J.-W, Kim Y, Lee WH, Kim SC (2018) Self-organizing Localization with Adaptive Weights for Wireless Sensor Networks. IEEE Sensors Journal 1-1.

67. Sahli N, Jabeur N, Khan IM, Badra M (2012) Towards a Generic Framework for Wireless Sensor Network Multi-Criteria Routing. 2012 5th International Conference on New Technologies, Mobility and Security.

68. Li J, Andrew L, Foh C, Zukerman M, Chen HH (2009) Connectivity, Coverage and Placement in Wireless Sensor Networks. Sensors 9(10): 7664-7693.

69. Choi JS, Zhou MC (2010) Recent Advances in Wireless Sensor Networks for Health Monitoring. International Journal of Intelligent Control and Systems 15(4): 49-58.

70. Jamie Eske J (2020) What can cause numbness in hands while sleeping? Medical News Today 1-2.

71. Kazemi A (2020) Fine-tuning locational formulations in mobile phone calls. Discourse Studies 22(5): 1-18.

72. Oliver N, Lepri B, Sterly H, Lambiotte R, Deletaille S, et al. (2020) Mobile phone data for informing public health actions across the COVID-19 pandemic life cycle. Science Advances 6(23): 1-7.

73. Nuria Oliver, Emmanuel Letouzé, Harald Sterly, Sébastien Delataille, et al. (2020) Mobile phone data and COVID-19: Missing an opportunity? 1-16.

74. Liaquat-Ali A, Imran U, Khatoon A, Fareed T, Afzal S, et al. (2020) Isolation and Identification of Microbes Causing Urinary Tract Infections from Hands and Mobile Phones. J Med Microb Diagn 306: 1-3.

75. Yasmin F, Nahar N, Banu B, Ali L, Sauerborn R, et al. (2020) The influence of mobile phone-basedhealth reminders on patient adherence tomedications and healthy lifestyle recommendations for effective management of diabetes type 2: arandomized control trial in Dhaka, Bangladesh. BMC Health Services Research 20: 520.

76. Miah MR, Rahman AAMS, Samdany AA, Chowdhury SH (2021) A Dynamic Scientific Model for Recovery of Corona Disease. Frontiers in Science 11(1): 1-17.

*Corresponding author: Rahimullah Miah. E-mail: drmrmiah@gmail.com/drmrmiah@yahoo.com/drmrmiah@nemc.edu.bd

\section{Next Submission with BGSR follows:}

- $\quad$ Rapid Peer Review

- $\quad$ Reprints for Original Copy

- E-Prints Availability

- Below URL for auxiliary Submission Link: https://biogenericpublishers.com/submit-manuscript/

Citation: Md Rahimullah Miah ${ }^{1, *}$, A A M Shazzadur Rahman², Mohammad Abdul Hannan ${ }^{3}$, Alamgir Adil Samdany ${ }^{4}$, Foujia Akhtar ${ }^{5}$, Md Sabbir Hossain ${ }^{6}$, S.A.M. Imran Hossain ${ }^{7}$, Md Shahariar Khan ${ }^{8}$, Md. Sher-E-Alam ${ }^{9}$, Jorin Tasnim Parisa ${ }^{10}$, Mohammad Basir Uddin ${ }^{11}$, Fuad Abdullah ${ }^{12}$, Chowdhury Shadman Shahriar ${ }^{13}$, Md Mehedi Hasan ${ }^{14}$, Alexander Kiew Sayok ${ }^{15}$, Ahi Sarok ${ }^{16}$, Mohammad Belal Uddin ${ }^{17}$, Motia Begum ${ }^{18}$, Jorin Tasnim Parisa ${ }^{19}$, Md Mokbul Hossain ${ }^{20}$, Mohammad Taimur Hossain Talukdar ${ }^{21}$, Shahriar Hussain Chowdhury ${ }^{22}$.Effect of Wireless Sensor Net-12 works to Increasing Causes of Numbness Op Acc J Bio Sci \& Res 9(1)-2021

DOI: 10.46718/JBGSR.2021.09.000217 